\title{
PERANCANGAN SISTEM LAYANAN INFORMASI AKADEMIK BERBASIS WEB PADA FAKULTAS TEKNIK UNIVERSITAS BHAYANGKARA JAKARTA RAYA
}

\author{
Dwi Swasono Rachmad \\ Teknik Informatika, Universitas Bhayangkara Jakarta Raya \\ dwi.swasono@dsn.ubharajaya.ac.id
}

Submitted August 20, 2019; Revised November 14, 2019; Accepted November 20, 2019

\begin{abstract}
Abstrak
Layanan Informasi Akademik pada suatu Fakultas sangat berperan penting untuk memberikan dan menyediakan informasi yang dibutuhkan oleh mahasiswa. Namun tidak demikian, dikarenakan fakultas teknik masih belum memberikan pelayanan dalam memberikan informasi yang akurat disebabkan belum adanya sistem informasi yang memfasilitasi segala kebutuhkan untuk pelayanan kepada mahasiswa. Oleh karena itu, diperlukan perancangan sistem informasi yang diharapkan dapat menjadi alat bantu bagi pihak fakultas dalam memberikan informasi dan juga memudahkan mahasiswa mendapatkan akses informasi dimana saja dan kapan saja tanpa perlu datang ke kampus untuk mengetahui informasi terkini. Dengan aplikasi berbasis web yang dapat diakses dengan perangkat mobile dan lainny maka informasi yang akan diperoleh untuk mahasiswa dapat diterima dengan cepat, tepat dan akurat dikarenakan pengelolaan sistem informasi tersebut dikelola langsung oleh pihak fakultas. Dengan demikian, mahasiswa mendapatkan informasi pada layanan informasi akademik fakultas teknik tanpa harus datang terlebih dahulu ke kampus, dengan menggunakan aplikasi berbasis web sebagai sistem informasi yang mudah di akses.
\end{abstract}

Kata Kunci : Sistem Akademik, Layanan, Web

\begin{abstract}
Academic Information Services at a Faculty is very important to provide and provide information needed by students. But this is not the case, because the faculty of engineering still does not provide services in providing accurate information due to the absence of an information system that facilitates all the requirements for services to students. Therefore, the need for designing this information system is expected to be a tool for the faculty in providing information and also makes it easier for students to get access to information anywhere and anytime without coming to campus to find out the latest information. With a web-based application that can be accessed by mobile devices and others, the information that will be obtained for students can be received quickly, precisely and accurately because the management of the information system is managed directly by the faculty. Thus, students get information on the Faculty of Engineering's academic information services without having to first come to campus, by using a web-based application as an information system that is easily accessed
\end{abstract}

Key Words : Information System, Service, Web

\section{PENDAHULUAN}

Dengan perkembangan ilmu pengetahuan dan teknologi yang begitu pesat dalam berbagai segi kehidupan tidak terkecuali teknologi komputer, membuatkomputer tidakhanya berguna dan bermanfaat baik secara individual, pendidikan, perushaan maupun disuatu instansi pemerintahan. Kehebatan teknologi komputer lainnya saat ini salah satunya internet. Terbukti dengan data statistik yang dilakukan Asosiasi Penyelenggara Jasa Internet (APJII) pada tahun 2017. Menurut hasil survey yang dilakukan APJII, masih cukup banyak masyarakat indonesia yang mengakses web browser untuk mencari sebuah informasi melalui komputer, laptop maupun smartphone. 
Penggunaan komputer ini harus sesuai dengan kebutuhan organisasi yang memakainya, baik software maupun hardware-nya agar komputer dapat dimanfaatkan sebaik mungkin. Dengan adanya aplikasi berbasis web pengguna dapat mengakses aplikasi tersebut dimana pun dengan sangat mudah dan cepat dengan menggunakan browser tanpa harus menginstall terlebih dahulu aplikasi tersebut untuk mendapatkan sebuah informasi.

Peran sistem informasi dalam lingkungan pendidikan sangatlah penting terutama pada pengolahan data-data dan kegiatankegiatan akademik maupun non akademik. Teknologi informasi menjadi salah satu pilihan utama dalam menciptakan sistem informasi yang sangat berguna bagi sebuah kebutuhan kampus. Pelayanan dalam sebuah instansi pendidikan adalah salah satu fakor pendorong terbentuknya kampus yang unggul dan memiliki nilai jual yang tinggi mengakibatkan terbentukya kebutuhan pelayanan akademik yang tinggi, sehingga akhirnya terbentuk sebuah sistem informasi yang dapat berguna bagi para mahasiswa. Memanfaatkan teknologi sebagai sumber informasi yang meningkatkan pelayanan informasi terhadap mahasiswa.

Dengan pemanfaatan teknologi ini maka dalam menyajikan informasi yang ada, mahasiswa dapat dengan mudah mengaksesnya tanpa batasan ruang dan waktu. Perguruan tinggi merupakan sebuah institusi dengan salah satu tugas yang dilakukannya adalah memberikan pelayanan kepada masyarakat untuk menyiapkan Sumber Daya Manusia (SDM) masa depan yang bermutu dan berdaya guna. Dalam prosesnya, perguruan tinggi membutuhkan sumber informasi yang terbaru. Pengembangan teknologi informasi dan komunikasi di perguruan tinggi merupakan upaya yang sudah seharusnya dilakukan.
Aktivitas utama dalam perguruan tinggi sesuai dengan fungsi utamanya yaitu sebagai penyelenggara pendidikan adalah layanan akademik. Dalam pelaksanaan layanan akademik ini perlu adanya penggunaan sistem yang dapat mendukung tercapainya layanan akademik tersebut. Seperti hal nya pada Universitas Bhayangkara Jakarta Raya yang telah menggunakan aplikasi berbasis web pada sistem informasi akademiknya(SIAKAD). Sistem informasi akademik merupakan sistem yang dapat diakses oleh mahasiswa, dosen dan tata usaha. Sistem untuk mahasiswa meliputi informasi jadwal kuliah, nilai (baik IPS maupun IPK). Biasanya sistem ini dilengkapi dengan password yang dibuat diawal masa perkuliahan.

Hal ini bertujuan supaya mahasiswa dapat memantau perkembangan nilai dengan mudah. Walaupun informasi dari sistem akademik yang sudah memadai namun, informasi mengenai pencarian jadwal dosen mengajar yang dilakukan pada sistem hanya bisa ditampilkan pada semester yang sedang mahasiswa jalankan, maupun informasi layanan seputar kegiatan administrasi akademik, perkuliahan dan informasi lainnya masih dilakukan secara manual, karena pada umumnya mahasiswa harus datang untuk melihatnya secara langsung pada lembaran kertas yang telah ditempel dipapan pengumuman atau cara lain mahasiswa mendapatkan sebuah informasi dengan datang ke tata usaha fakultas teknik untuk bertanya seputar informasi terbaru.

Berdasarkan dari latar belakang masalah diatas, dibutuhkan sebuah sistem informasi yang dapat memudahkan mahasiswa untuk mengakses dan mendapatkan informasi tanpa harus login terlebih dahulu, atau mencari satu persatu jadwal dosen secara manual. Oleh karena itu, maka penulis tertarik untuk membuat penelitian dengan judul “ PERANCANGAN SISTEM 


\section{LAYANAN INFORMASI AKADEMIK BERBASIS WEB FAKULTAS TEKNIK UNIVERSITAS BHAYANGKARA JAKARTA RAYA"}

Latar belakang yang telah diuraikan diatas, maka dapat di identifikasikan masalah yang ada sebagai berikut :

1. Kurangnya penyampaian informasi yang tepat dan akurat untuk mahasiswa berupa informasi perkuliahan diantaranya kalender akademik, daftar mata kuliah, daftar pembimbing akademik, kemudian pencarian jadwal dosen, informasi layanan akademik seperti form magang atau form riset dan informasi administrasi akademik diantaranya; daftar ulang, cuti akademik, tidak aktif kuliah, yang disampaikan masih berupa paperbased.

2. Masih terbatasnya akses untuk mendapatkan informasi. Karena, mahasiwa harus terlebih dahulu datang ke kampus untuk melihat dan mengetahui informasi terbaru melalui papan pengumuman.

3. Belum adanya sistem yang mempermudah mahasiswa dalam mendapatkan layanan informasi akademik tanpa harus datang langsung kebagian tata usaha fakultas teknik.

4. Belum adanya sistem yang dapat diakses secara langsung tanpa harus melakukan login , untuk mendapatkan informasi perkuliahan, pencarian jadwal dosen secara keseluruhan, dan informasi administrasi akademik.

Dalam penulisan ini diperlukan adanya pembatasan dari permasalahan yang timbul dalam pembahasan yang akan dilakukan:

1. Ruang lingkup pada penelitian ini hanya membahas pada Fakultas Teknik khususnya pada prodi
Teknik Informatika di Universitas Bhayangkara Jakarta Raya

2. Pengembangan sistem ini berbasis web, untuk dapat mengolah data menjadi sebuah informasi yang bersifat berkelanjutan.

3. Informasi yang ditampilkan meliputi informasi layanan seperti form untuk surat riset atau magang, kalender akademik dan pencarian data dengan cara melakukan penginputan nama dosen dan kelas.

Berdasarkan penulisan diatas akan diuraikan tujuan penelitian sebagai berikut:

1. Memudahkan mahasiwa untuk mendapatkan informasi yang informatif tentang segala informasi akademik.

2. Memudahkan mahasiswa untuk mendapatkan informasi tanpa harus datang langsung ke ruang tata usaha fakultas teknik dan dapat diakses dengan mudah dimana saja, kapan saja secara realtime.

3. Menciptakan kebebasan informasi untuk di sistem informasi akademik.

4. Menciptakan keterbukaan informasi yang dapat diakses berulang kali tanpa harus ada batasan untuk mendapatkan informasi.

\section{METODE PENELITIAN}

Dalam penelitian, ada beberapa tahap yang dilakukan dalam proses penelitian ini. Diantaranya sebagai berikut:

\section{Objek Penelitian}

Objek penelitian merupakan permasalahan yang diteliti. Objek dari penelitian ini adalah dilakukan untuk mengembangkan suatu Sistem Informasi. Objek penelitian yang dilakukan pada penulisan ini ada pada Universitas Bhayangkara Jakarta Raya, yang hanya 
mencakup pada ruang lingkup Fakultas Teknik.

\section{Sejarah}

Universitas

Bhayangkara Jakarta Raya

Universitas Bhayangkara Jakarta Raya adalah salah satu Perguruan Tinggi Swasta yang berada dibawah pembinaan Yayasan Brata Bhakti. Sebagai salah satu institusi pendidikan tinggi yang mengemban tugas yaitu pendidikan dan pengajaran, penelitian, dan pengabdian kepada masyarakat. Universitas Bhayangkara didirikan berdasarkan keputusan Kepala Kepolisian Republik Indonesia selaku ketua umum Yayasan Brata Bhakti Polri Nomor Pol: KEP/05/IX1995 tanggal 18 September 1995 dan keputusan Menteri Pendidikan dan Kebudayaan RI Nomor : 074/D/O/1995 tanggal 8 September 1995 merupakan bagian dari sistem pendidikan tinggi nasional yang berada dibawah pembinaan Yayasan Brata Bhakti sebagai badan penyelenggara. Universitas Bhayangkara Jaya harus menyusun suatu garis pedoman berupa petunjuk tentang Administrasi Akademik, agar dapat dijadikan sebagai haluan dalam implementasi pelaksanaan akademik di Universitas Bhayangkara Jakarta Raya

\section{Profil Fakultas Teknik}

Universitas Bhayangkara Jakarta Raya mempunyai 5 Fakultas diantaranya adalah; Fakultas Hukum, Fakultas Psikologi, Fakultas Ekonomi, Fakultas Ilmu Komunikasidan, FakultasTeknik. Fakultas Teknik Universitas Bhayangkara Jakarta Raya merupakan salah satu dari beberapa fakultas yang terdapat pada Universitas Bhayangkara Jakarta Raya. Fakultas Teknik memiliki beberapa Program Studi diantaranya: Teknik Informatika, Kimia, Industri, Lingkungan dan Perminyakan. Fakultas Teknik sendiri memiliki visi dan misi.

\section{Kerangka Penelitian}

Kerangka penelitian dibuat untuk memperjelas proses berjalannya penelitian sampai denganalur pengembangan aplikasi. Berikut merupakan kerangka alur penelitian perancangan aplikasi sistem layanan informasi akademik pada Fakultas Teknik.

\section{A. Perumusan Masalah}

Berdasarkan identifikasi masalah yang ditemukan mengenai sistem layanan informasi kegiatan akademik yang masih bersifat manual yang mengharuskan mahasiswa terlebih dahulu datang ke kampus untuk mendaptkan informasi terbaru.

\section{B. Pengumpulan Data}

Metode pengumpulan data yang penulis lakukan adalah dimulai dengan melakukan observasi langsung ke objek penelitian dan melakukan wawancara terhadap Kepala Bagian Tata Usaha pada Fakultas Teknik Universitas Bhayangkara yang terkait dengan permasalahan yang sedang penulis teliti.

\section{Perancangan Aplikasi}

Mendesain metode penelitian yang akan digunakan, mulai dari pengumpulan data hingga menganalisanya, dan membuat menu dan submenu apa saja yang akan ditampilkan pada sistem informasi tersebut.

\section{Pengujian}

Pengujian sistem layanan informasi akademik ini menggunakan pengujian black boxtesting yaitu pengujian unuk 
menguji sistem dan user interface oleh pengguna. Pengujian ini dilakukan untuk memastikan apakah sistem yang dibuat sudah sesuai dengan yang diharapkan atau berhasil menampilkan output sesuai dengan rancangan.

\section{E. Implementasi}

Dalam tahap ini penulis melakukan implementasi dan permasalahan yang ada pada Fakultas Teknik Universitas Bhayangkara Jakarta Raya.

\section{F. Analisis Sistem Berjalan}

Analisis sistem berjalan adalah penguraian dalam suatu sistem informasi yang utuh ke dalam komponennya yang bertujuan untuk mengidentifikasi dan mengevaluasi setiap permasalahan, hambatan, yang terjadi dan kebutuhan agar dapat melakukan perbaikan. Analisis kebutuhan aplikasi dilakukan untuk mengetahui kebutuhan pengguna terhadap aplikasi yang dikembangkan Hal ini perlu dilakukan agar aplikasi yang dikembangkan sesuai dengan kebutuhan pengguna. Di bagian ini juga dijelaskan siapa saja yang akan menggunakan aplikasi in dan informasi apa saja yang digunakan oleh mereka.

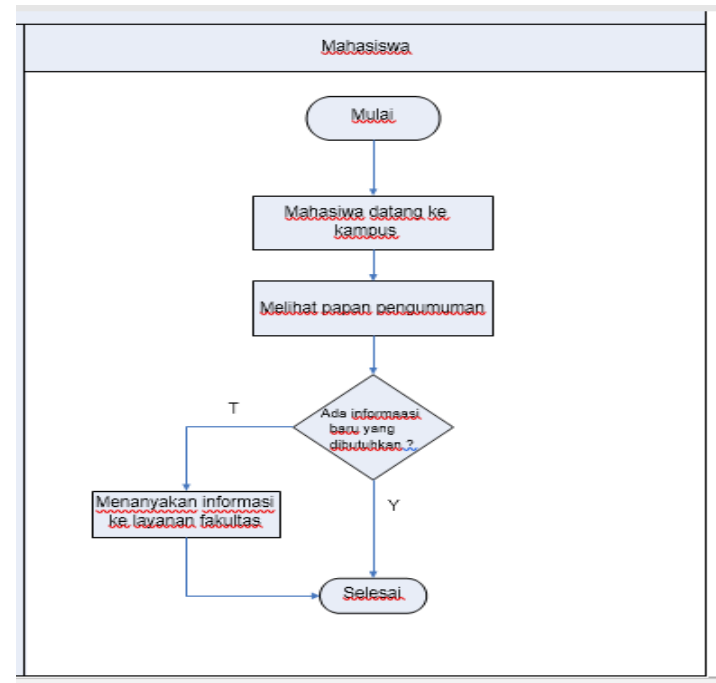

Gambar 1. Flowchart Analisis Sistem Berjalan

\section{G. Permasalahan}

Analisa yang dilakukan secara langsung dengan mengumpulkan data dari narasumber, terdapat beberapa masalah yang terjadi. Adapun masalah yang terjadi adalah:

1. Mahasiswa masih kurang peduli dengan informasi yang ada dikampus.

2. Belum maksimalnya pelayanan informasi pada Fakultas Teknik .

3. Masih banyaknya penggunaan paperbased di madding untuk menyampaikan informasi

4. Informasi yang diberikan masih bersifat dadakan dan belum terstruktur dengan baik.

5. Sistem informasi yang sudah ada masih sering terjadi error sehingga sering dibutuhkan waktu untuk maintenance.

\section{H. Analisis Usulan Sistem}

Berdasarkan permasalahan yang terjadi, analisa kebutuhan sistem ini adalah proses pemecahan masalah yang sedang terjadi. Sehingga pada akhirnya dibutuhkannya sebuah sistem yang akan dikembangkan untuk menyelesaikan semua permasalahan yang terjadi pada penyampaian informasi kepada civitas kampus.

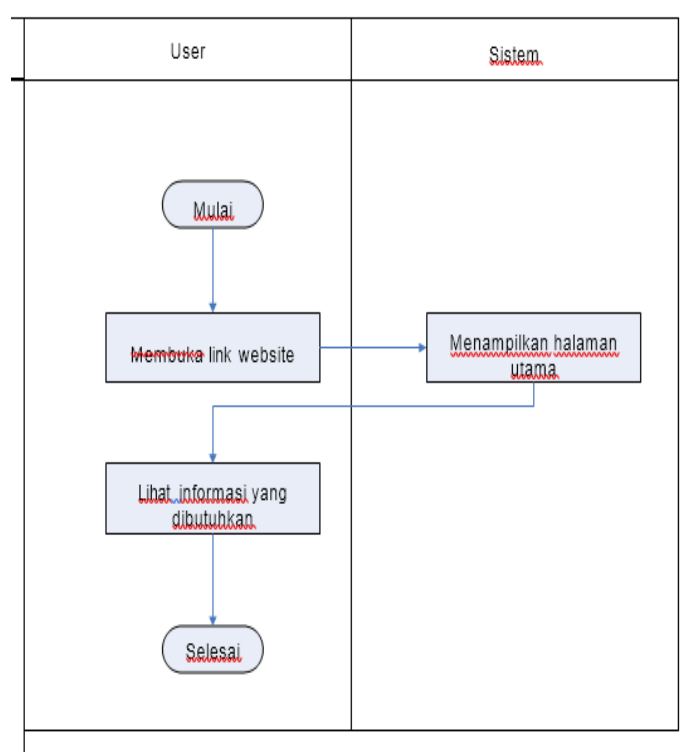

Gambar 2. Flowmap Analisis Usulan Sistem 


\section{Populasi}

Populasi adalah wilayah generalisasi yang terdiri atas obyek/subyek yang mempunyai kualitas dan karakteristik tertentu yang ditetapkan oleh peneliti untuk dipelajari kemudian ditarik kesimpulannya [4]. Dari pengertian diatas dapat dikatakan bahwa populasi merupakan objek atau subjek yang berada pada suatu wilayah yang memenuhi syarat tertentu yang berkaitan dengan masalah penelitian.

Populasi adalah gabungan dari seluruh elemen yang terbentuk peristiwa, hal, atau orang yang memiliki karakteristik serupa yang menjadi pusat perhatian peneliti, karena dipandang sebagai semesta penelitian [2]. Populasi adalah wilayah generalisasi yang terdiri atas objek/subjek yang mempunyai kualitas dan karakteristik tertentu yang ditetapkan oleh peneliti untuk dipelajari dan kemudian ditarik kesimpulan [5].

Dalam proses pengumpulan data tersebut penulis memberikan kuesioner kepada seluruh mahasiswa Teknik Universitas Bhayangkara Jakarta Raya sebagai populasi penelitian. Kemudian dari populasi tersebut ditentukan sampel secara acak. Berdasarkan penjelasan diatas, populasi dalam penelitian ini adalah mahasiswa teknik pada data pelaporan tahun 2018/2019 yang diambil dari data forlap dikti sebagai berikut:

\section{Tabel 1 Data Mahasiswa Teknik 2018/2019}

\begin{tabular}{|c|c|c|c|c|c|c|c|}
\hline \multirow{2}{*}{ No } & \multirow{2}{*}{$\begin{array}{l}\text { Kode } \\
\text { Prodi }\end{array}$} & \multirow{2}{*}{$\begin{array}{l}\text { Nama } \\
\text { Program } \\
\text { Studi } \\
\end{array}$} & \multirow{2}{*}{ Jenjang } & \multirow{2}{*}{ Status } & \multirow{2}{*}{$\begin{array}{l}\text { Pergurdana } \\
\text { Tinggi }\end{array}$} & \multicolumn{2}{|c|}{$\begin{array}{l}\text { Data Pelaporan } \\
\text { Tahun 2018/2019 }\end{array}$} \\
\hline & & & & & & $\begin{array}{l}\text { Jumlah } \\
\text { Dosent }\end{array}$ & $\begin{array}{l}\text { Jumlah } \\
\text { Mhss } \\
\end{array}$ \\
\hline 1 & 26201 & $\begin{array}{l}\text { Teknik } \\
\text { Informatika }\end{array}$ & S1 & Aktif & \begin{tabular}{|l} 
Universitas \\
Bhaxangkara \\
Jakarta Raya
\end{tabular} & 33 & 1722 \\
\hline 2 & 55201 & $\begin{array}{l}\text { Teknik } \\
\text { Industri }\end{array}$ & S1 & Altif & \begin{tabular}{|l|} 
Universitas \\
Bhavangkara \\
Jakarta Raya
\end{tabular} & 47 & 1557 \\
\hline 3 & 24201 & $\begin{array}{l}\text { Teknik } \\
\text { Kimia }\end{array}$ & S1 & Alktif & $\begin{array}{l}\text { Universitas } \\
\text { Bhaxaangkara } \\
\text { Jakarta Raya }\end{array}$ & 9 & 219 \\
\hline 4 & 25201 & $\begin{array}{l}\text { Teknik } \\
\text { Lingkungan }\end{array}$ & S1 & Altif & \begin{tabular}{|l} 
Universitas \\
Bhavangkara \\
Jakarta Raya \\
\end{tabular} & 7 & 73 \\
\hline 5 & 32201 & $\begin{array}{l}\text { Teknik } \\
\text { Perminyakan }\end{array}$ & S1 & Aktif & \begin{tabular}{|l} 
Universitas \\
Bhaxangkara \\
Jakarta Raya
\end{tabular} & 6 & 195 \\
\hline
\end{tabular}

Dilakukan karena peneliti memiliki keterbatasan dalam melakukan penelitian baik dari segi waktu, tenaga, dana, dan jumlah populasi yang sangat banyak.

Pengukuran sampel merupakan langkah untuk menentukan sampel yang diambil untuk melaksanakan penelitian. Untuk menghitung penentuan jumlah sampel dari populasi tertentu yang dikembangkan, maka digunakan rumus Slovin sebagai berikut, Rumus :

$\mathrm{n}=\mathrm{N} / \mathrm{N}(\mathrm{d})^{2}+1$

Dimana:

$\mathrm{n}=$ Ukuran Sampel.

$\mathrm{N}=$ Ukuran populasi yang diketahui.

$\mathrm{d}=$ Persen kelonggaran ketidaktelitian karena kesalahan pengambilan sampel, presisi yang diinginkan adalah $10 \%$.

$$
\begin{aligned}
& \text { Perhitungan : } \\
& \mathrm{n}=\frac{3646}{(3646 \times 0.01)+1}=\underline{3646}=97.34
\end{aligned}
$$

Pembulatan menjadi 97

Setelah diketahui sampel yang diteliti adalah 97 responden dari 5 jurusan yang ada pada fakultas teknik, maka dengan memasukan jumlah tersebut kedalam rumus diatas dan menentukan tingkat kesalahan $10 \%$, maka jumlah minimum yang harus diambil untuk mewakili populasi yaitu sebesar 80 responden.

\section{K. Validitas}

Validitas merupakan derajad ketepatan antara data yang terjadi pada objek penelitian dengan data yang dilaporkan oleh peneliti [4]. Dinyatakan valid jika instrmen tersebut dapat digunakan untuk mengukur apa yang seharusnya diukur. Syarat yang harus dipenuhi yaitu harus memiliki kriteria sebagai berikut [4]: 
a. Jika $r>0,3$ maka item- item tersebut dinyatakan valid.

b. Jika $r<0,3$ maka item-item tersebut dinyatakan tidak valid. Uji validitas instrumen dapat menggunakan rumus korelasi.

Tabel 2. Hasil Uji Validitas

\begin{tabular}{|l|l|l|l|l|c|}
\hline \multicolumn{1}{|c|}{ No } & P1 & P2 & P3 & P4 & P5 \\
\hline $\begin{array}{l}\text { R } \\
\text { Hitung }\end{array}$ & 0.32 & 0.64 & 0.79 & 0.85 & 0.67 \\
\hline $\begin{array}{l}\text { R } \\
\text { Tabel }\end{array}$ & 0.25 & 0.25 & 0.25 & 0.25 & 0.25 \\
\hline Hasil & Valid & Valid & Valid & Valid & Valid \\
\hline
\end{tabular}

Analisis uji validitas

a. Populasi responden 97 orang.

b. Hasil uji validitas data menunjukkan semua butir pertanyaan valid, karena nilai $r$ hitung lebih besar dari $r$ table.

\section{Reliabilitas}

Reliabilitas adalah untuk mengetahui sejauh mana hasil pengukuran tetap konsisten, apabila dilakukan pengukuran dua kali atau lebih terhadap gejala yang sama dengan menggunakan alat pengukur yang sama [4].

$$
r_{11}=\left[\frac{n}{(n-1)}\right]\left[1-\frac{\sum \sigma_{t}^{2}}{\sigma_{t}{ }^{2}}\right]
$$

Kriteria uji reliabilitas dengan rumus alpha adalah apabila $r$ hitung $>r$ tabel, maka alat ukur tersebut reliabel dan juga sebaliknya, jika $r$ hitung < r tabel maka alat ukur tidak reliabel. Jika instrumen itu valid, maka dilihat kriteria penafsiran mengenai individual sebagi berikut:

a. Antara 0,800 sampai dengan 1,000 : tinggi

b. Antara 0,600 sampai dengan 0,800 :cukup

c. Antara 0,400 sampai dengan 0,600 :agak rendah d. Antara 0,200 sampai dengan 0,400 :rendah

e. Antara 0,000 sampai dengan 0,200: sangat rendah

Tabel 3 Hasil Uji Reliabilitas

\begin{tabular}{|l|c|c|c|c|c|}
\hline \multicolumn{1}{|c|}{ No } & P1 & P2 & P3 & P4 & P5 \\
\hline Varian Xi & 0.34 & 0.28 & 0.27 & 0.29 & 0.45 \\
\hline $\begin{array}{l}\text { Varian } \\
\text { Total }\end{array}$ & \multicolumn{5}{|c|}{$\mathbf{3 . 4 9 9 6}$} \\
\hline Reliabilitas & \multicolumn{5}{|c|}{$\mathbf{0 . 6 5 8}$} \\
\hline
\end{tabular}

\section{HASIL DAN PEMBAHASAN}

\section{Perancangan}

Tahap pemodelan data dilakukan setelah tahap pemodelan bisnis selesai dilaksanakan dan didefinisikan secara jelas. Dalam tahap ini digmbarkan lebih rinci berdasarkan tahap berikutnya sehingga diperoleh detail data dan aliran proses sistem informasi layananakademik melaluistruktur tabel dan relasi tabel

\section{Permodelan Proses}

\section{a. Use Case Diagram}

Aktor yang dapat berinteraksi dengan sistem. Berikut ini rancangan UseCase pada penelitian ini :

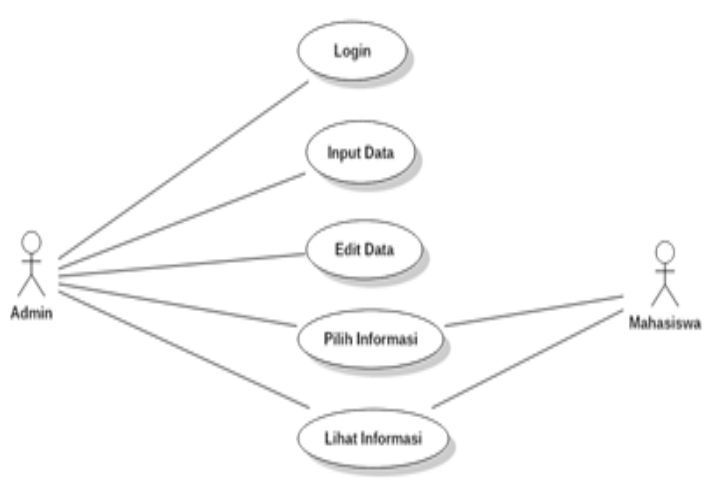

Gambar 3. Use Case Diagram SLIA 
Pada gambar use case diagram layanan informasi akademik pada fakultas teknik, mempunyai 2 aktor yaitu : admin dan mahasiswa. Untuk dapat bisa masuk ke dalam sistem admin bisa langsung melakukan login, kemudian bisa menginput dan mengedit data yang dibutuhkan, setelah itu dapat memilih dan melihat informasi yang sudah selesai ditambahkan. Sedangkan mahasiswa bisa langsung mengakses tanpa harus login terlebih dahulu dan langsung bisa memilih dan melihat informasi yang diiinginkan.

Use case diagram tidak menjelaskan secara detail tentang penggunaan tiap use case, namun hanya memberi gambaran singkat hubungan antara use case, aktor, dan sistem, melalui use case diagram kita dapat mengetahui fungsi-fungsi apa saja yang ada pada sistem [1].

\section{b. Activity Diagram}

Berikut adalah activity diagram menggambarkan aktifitas-aktifitasyang terjadi dalam sistem pelayanan informasi akademik :

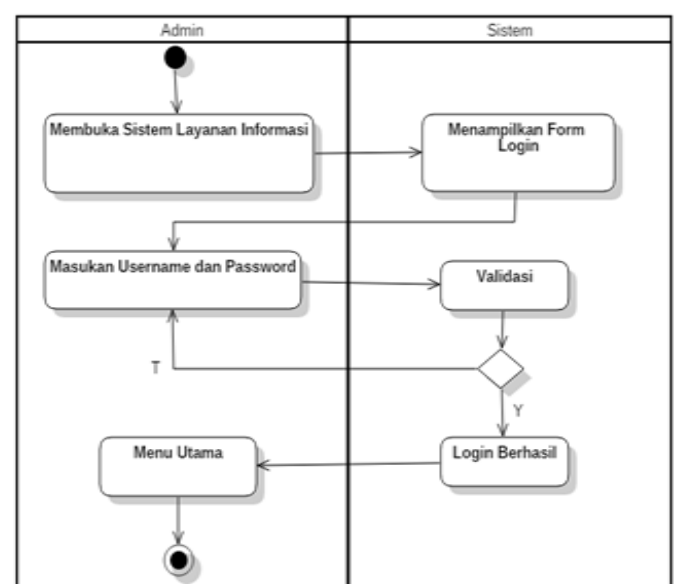

Gambar 4. Activity Diagram Admin

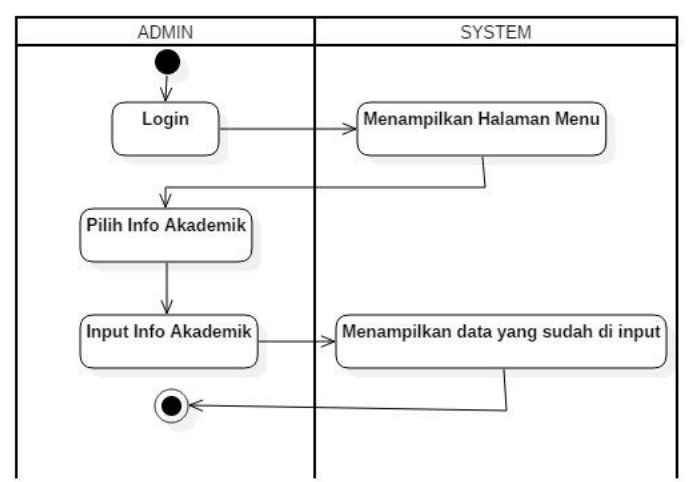

Gambar 5. Activity Diagram Admin Menu Input Info Akademik

\section{Class Diagram}

Rancangan yang dibangun dari sistem yang dibangun menggunakan class diagram, dimana class diagram menjelaskan class- class yang adapada sistem yang dibangun. Class diagram tersebut menggabarkan struktur statis dari sebuah sitem, objek- objek yang dipakai, dan hubungan antar class yang ada. Class diagram dengan sistem yang diusulkan dapat dilihat sebagai berikut :

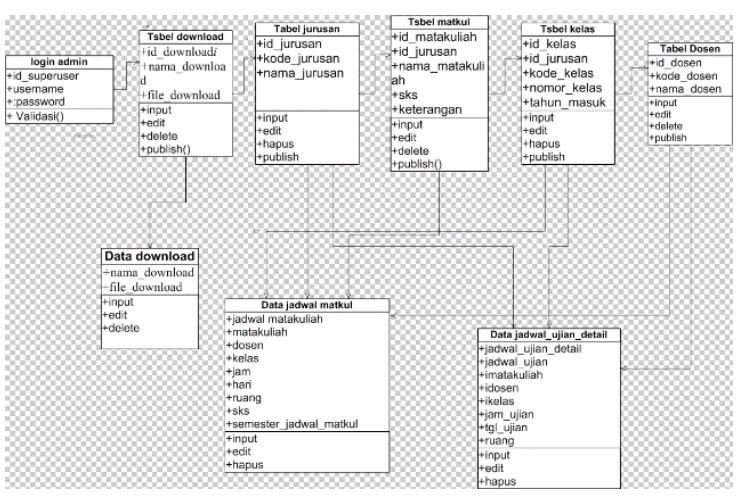

Gambar 6. Class Diagram

\section{Implementasi}

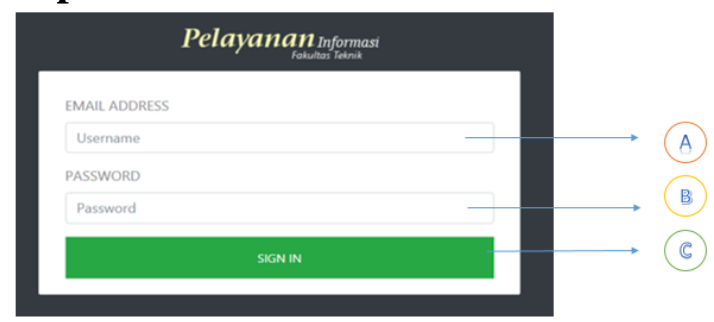

Gambar 7. Implementasi Interface Menu Login 
Keterangan :

a. Memasukan username yang sudah ditentukan pada database admin.

b. Memasukan pasword yang sudah ditentukan pada database admin.

c. Untuk memproses setelah memasukan username dan password yang tersedia dan mengakses admin untuk masuk ke halaman utama web.

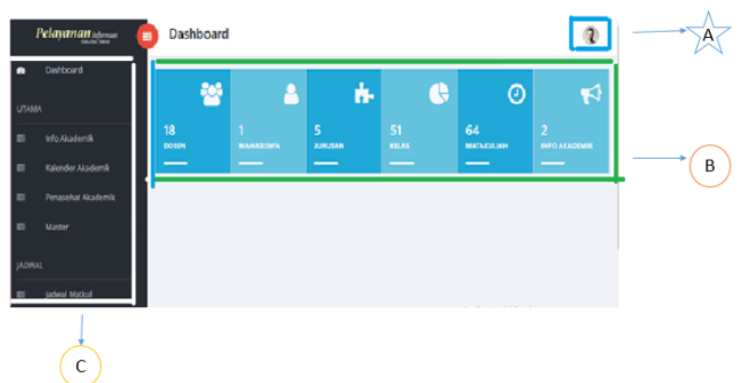

\section{Gambar 8. Implementasi Interface Admin Halaman Utama Web}

Interface ini menjelaskan tentang tampilan halaman utama yang terdapat beberapa menu yang bisa digunakan oleh admin sebagaimana keperluannya.

Keterangan :

a. Administrator, menjelaskan bahwa admin sudah berhasil masuk pada halaman utama website.

b. Submenu yang terdiri dari data dosen, data mahasiswa, data jurusan, data mata kuliah, dan info akademik.

c. Menu Dashboard yang terdiri dari info akademik, kalender akademik, penasehat akademik, master, dan jadwal mata kuliah.

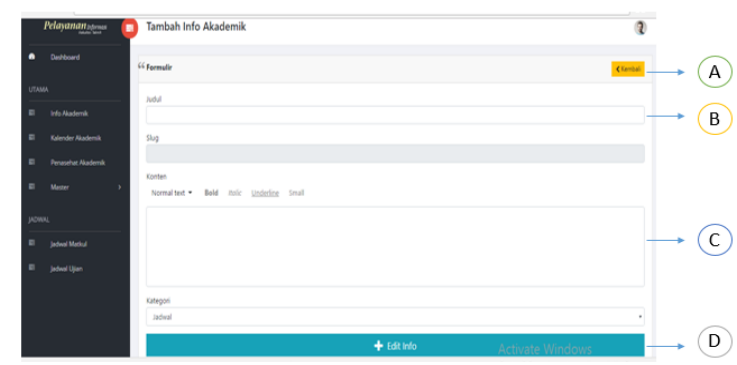

Gambar 9. Implementasi Interface Menu Input Akademik
Interface ini menjelaskan tentang proses penambahan informasi akademik yang nantinya akan muncul pada sistem layanan informasi akademik

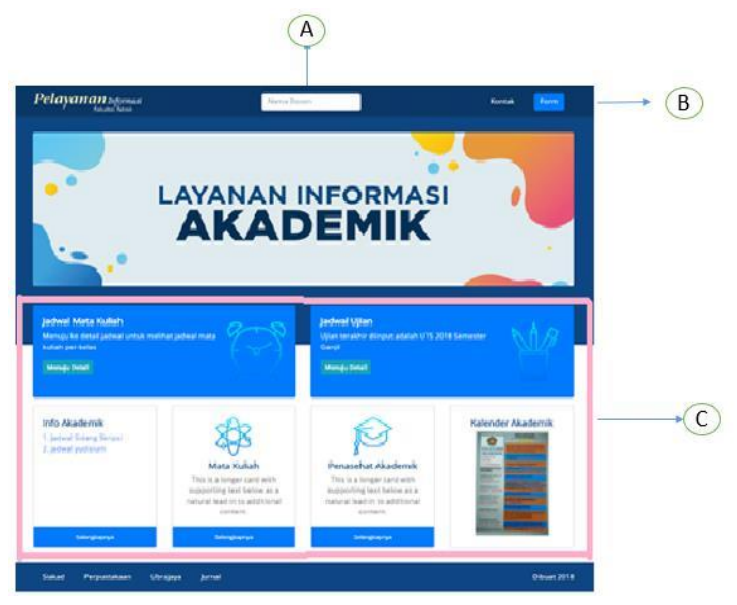

\section{Gambar 10 Implementasi Interface Home Sistem Layanan Informasi Akademik}

Interface ini menunjukkan tentang tampilan halaman utama pada aplikasi.

Keterangan :

a. Memasukan nama dosen/kelas untuk mencari jadwal dosen.

b. Form yang berisi form magang dan form riset.

c. Menu terdiri dari jadwal mata kuliah, jadwal ujian, info akademik, mata kuliah, penasehat akademik, dan kalender akademik.

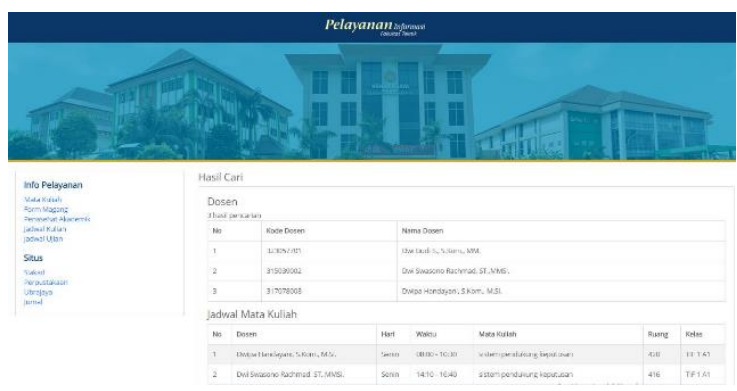

\section{Gambar 11. Implementasi Interface Hasil Pencarian}

Interface ini menampilkan hasil pencarian pada sistem layanan informasi akademik dengan cara menginput nama dosen / kelas. 


\section{Proses Pengujian Black Box}

Pada tahap selanjutnya setelah selesai membuat sebuah sistem baru berbasis web dan android langkah selanjutnya adalah melakukan sebuah pengujian, adapun tujuan dilakukannya pengujian ini adalah untuk dapat mengetahui apakah sistem yang sudah dibuat ini dapat berfungsi dengan baik sesuai yang diharapkan atau tidak. Pengujian dilakukan denga nmenggunakan metode black box, pengujian dengan metode ini berfokus pada sebuah fungsional suatu programatau aplikasi.

Tabel 4. Hasil Pengujian Black Box

\begin{tabular}{cll}
\hline No & \multicolumn{1}{c}{ Menu } & Hasil Uji \\
\hline 1 & Login Admin & Berhasil \\
2 & Akses Halaman Utama Web & Berhasil \\
3 & Menu Info Akademik & Berhasil \\
4 & Menu Kalender Akademik & Berhasil \\
5 & Menu Penasehat Akademik & Berhasil \\
6 & Menu Jadwal MatKul & Berhasil \\
7 & Menu Jadwal Ujian & Berhasil \\
8 & Main Web Sistem Layanan & Berhasil \\
9 & Menu Search Kelas/Dosen & Berhasil \\
10 & Menu Form & Berhasil \\
11 & Menu Kontak & Berhasil \\
12 & Menu Mitra Universitas & Berhasil \\
\hline
\end{tabular}

\section{SIMPULAN}

Berdasarkan dari hasil pembahasan dan penelitian, maka dapat ditarik kesimpulan sebagai berikut :

a. Mahasiswa akan lebih mudah mendapatkan informasi yang dibutuhkan secara tepat dan akurat tanpa datang terlebih dahulu ke kampus.

b. Dengan adanya sistem ini memberi kemudahan bagi Mahasiswa dalam mendapatkan informasi jadwal dosen dan mendapatkan form magang atau riset.

c. Sistem informasi layanan informasi akademik ini menampilkan pencarian jadwal dosen dengan menginput nama dosen dan kelas, menampilkan daftar matakuliah, daftar pembimbing akademik.

d. Sistem ini dapat membantu mahasiswa dalam mendapatkan informasi pencarianj adwal dosen tanpa harus log in terlebih dahulu, dan membantu pihak fakultas dalam mengolah data dan menyampaikan informasi.

\section{DAFTAR PUSTAKA}

[1]. A.S Rosa dan Salahuddin M. Modul Pembelajaran Rekayasa Perangkat Lunak (Terstruktur dan Berorientasi Objek). Bandung: Modula, 2011

[2]. Augusty, Ferdinand. Metode Penelitian Manajemen: Pedoman Penelitian untuk skripsi, Tesis dan Disertai Ilmu Manajemen. Semarang: Universitas Diponegoro, 2006

[3]. Sugiyono. Metode Penelitian Pendidikan. Bandung: Alfabeta, 2012.

[4]. Sugiyono. MetodePenelitian Kuantitatif Kualitatif dan R\&D.Bandung: Alfabeta, 2014

[5]. Sujarweni, V. W., \& Endrayanto, P. Statistika Untuk Penelitian. Yogyakarta: Graha Ilmu, 2012 